\title{
Geomicrobiological study of modern microbialites from Mexico: towards a better understanding of the ancient fossil record
}

\author{
K. Benzerara ${ }^{1}$, E. Couradeau ${ }^{1,2}$, E. Gérard ${ }^{3}$, R. Tavera ${ }^{4}$, A. I. Lopez-Archilla ${ }^{5}$, D. Moreira ${ }^{2}$, P. Lopez-
} Garcia $^{2}$

${ }^{1}$ Institut de Minéralogie et de Physique de la Matière Condensée, CNRS UMR 7590, Université Pierre et Marie Curie, 75005 Paris, France

${ }^{2}$ Unité d'Ecologie, Systématique et Evolution, CNRS UMR 8079, Université Paris-Sud, 91405 Orsay Cedex, France

${ }^{3}$ Institut de Physique du Globe de Paris (IPGP), CNRS UMR 7154, Université Paris Diderot, 75005

Paris, France

${ }^{4}$ Departamento de Ecología y Recursos Naturales, Universidad Nacional Autónoma de México, DF Mexico, Mexico

${ }^{5}$ Universidad Autónoma de Madrid, Department of Ecology, 28049 Madrid, Spain

\begin{abstract}
Microbialites are sedimentary formations that are found throughout the geological record and are usually considered as one of the oldest traces of life on Earth. Although they have been known for more than a century and hold as an emblematic object in Earth Sciences, we yet do not understand in details how they form and how microbial processes impact their chemistry, structure and macroscopic morphology. Here, we show recent advances achieved owing to funding provided by the EPOV program on the formation of modern microbialites in the crater Lake Alchichica (Mexico). We first show that very diverse microbial communities populate these microbialites, including diverse microbial groups able to induce carbonate precipitation. We demonstrate that this microbial diversity can be preserved for several years in laboratory aquaria offering a nice opportunity for future studies to assess the relationships between biodiversity and microbialite formation. We then detail the textural modifications affecting cyanobacterial cells during the first steps of fossilization as captured in Alchichica microbialites. Finally, we report the discovery of a new deepbranching cyanobacterium species, Candidatus Gloeomargarita lithophora, able to form intracellular $\mathrm{Ca}-, \mathrm{Mg}-$, Sr- and Ba-rich carbonates and discuss the implications for the interpretation of the fossil record.
\end{abstract}




\section{Introduction}

Microbialites are sedimentary structures, often composed of carbonates that are constructed by microorganisms [e.g., 1]. Stromatolites are one famous particular type of microbialites that show a laminated macrofabric. Microbialites are central in geomicrobiology for several reasons: 1 . They are found throughout the geological record and are usually considered as one of the oldest traces of life on Earth [e.g., 2]. 2. Moreover, they likely had a major impact on the development of the early atmosphere, through photosynthetic consumption of the greenhouse gas $\mathrm{CO}_{2}$ and production of free oxygen. 3. They are an outstanding model for biomineralogy and microbial ecology offering multiple interactions between complex microbial communities, their polymers and their environment, in particular mineral phases that might induce stress conditions or be beneficial to the microorganisms [e.g., 3].

Although they have been known for more than a century [4] and hold as an emblematic object in Earth Sciences, we still do not understand in details how they form and how microbial processes impact their chemistry, structure and macroscopic morphology. For example, abiotic processes have been proposed as alternative mechanisms for the formation of morphologically similar objects [e.g., 5]. It is thus not clear from recent literature what unambiguously signs a microbial activity in ancient microbialites. Such an ambiguity limits obviously their use as reliable paleobiological proxies.

The old paradigm is that microbialite formation is based mostly on the activity of cyanobacteria as a trigger to precipitation of carbonates. However, this has been significantly questioned over the last few years: First, other microbial metabolisms inducing carbonate precipitation operate as well in modern microbialites, in particular sulphate-reduction [e.g. 6] and may thus be key drivers in the formation of microbialites; similarly, Bosak et al. [7] proposed that anoxygenic phototrophs may have contributed to the formation of ancient microbialites. Other studies have stressed on the inhibitory effect of organic polymers such as extracellular polymeric substances (EPS) on the precipitation of carbonates [e.g., 8] and proposed that heterotrophs, including sulphate-reducing bacteria, may favor lithification by degrading organic molecules [e.g. 9, 10]. Hence, the process of microbialite formation most likely results from the interplay between microorganisms forming complex communities and their metabolic activities under the influence of environmental conditions (e.g. photoperiod, temperature) and local chemistry (ion availability). As a result, the characterization of the microbial diversity present in microbialites is a crucial step to further understand their precise interactions with minerals [11]. This is also crucial to understand if the study of past microbialites can tell us something about microbial metabolisms that existed at that time and how their activity is recorded.

Fossilization of microbial cells is one particular consequence of the biomineralization processes occurring in microbialites and an important issue for the search of ancient traces of life [e.g., 8, 12]. Microfossils have for example been found repeatedly in ancient microbialites [e.g., 13, 14]. However, we still have a poor knowledge on the fineness of the microbial structures that can be fossilized. Another question that remains unanswered is whether variations in the extent of cell fossilization are related to environmental conditions such as $\mathrm{pCO}_{2}$ (in that case presence/absence of fossils in microbialites would be a paleoenvironmental proxy, e.g. [15]) or varying specific susceptibilities of cells to fossilization, i.e. some species encrust more easily than others [e.g., 16]. Alchichica microbialites, where the mineral encrustation of specific cyanobacteria $[17,18]$ and a new cyanobacterial species forming intracellular carbonates were discovered [19], offered particularly interesting clues on these questions.

The crater lake of Alchichica is an alkaline ( $\mathrm{pH} ~ 8.9)$ lake with a maximum depth of $63 \mathrm{~m}$ located in the Central Mexico Plateau at an altitude of $2300 \mathrm{~m}$ above sea level. The lake harbors prominent living microbialites that develop down to at least $14 \mathrm{~m}$ in depth [20] (Figure 1). Alchichica is a monomictic lake, i.e. the oxygenated surface water mixes with deep anoxic water once a year during the winter season from January to late March or early April [21], and remains stratified the rest of the year, with significant resulting modifications of the chemistry of the lake [22]. Studies on the 
hydrochemistry of the lake $[20,23]$ showed that water is $\mathrm{Mg}$-rich $(\mathrm{Mg} / \mathrm{Ca}=40)$ and oversaturated with calcium and magnesium carbonates. Accordingly, Alchichica microbialites are predominantly composed of hydromagnesite $\left[\mathrm{Mg}_{5}\left(\mathrm{CO}_{3}\right)_{4}(\mathrm{OH})_{2} \cdot 4\left(\mathrm{H}_{2} \mathrm{O}\right)\right]$ and aragonite $\left(\mathrm{CaCO}_{3}\right)$ [20]. In this project, we first studied the microbial diversity associated with Alchichica microbialites, then we investigated the calcification of some cyanobacteria at the submicrometer-scale. We finally discovered a new cyanobacterial species forming intracellular carbonates.
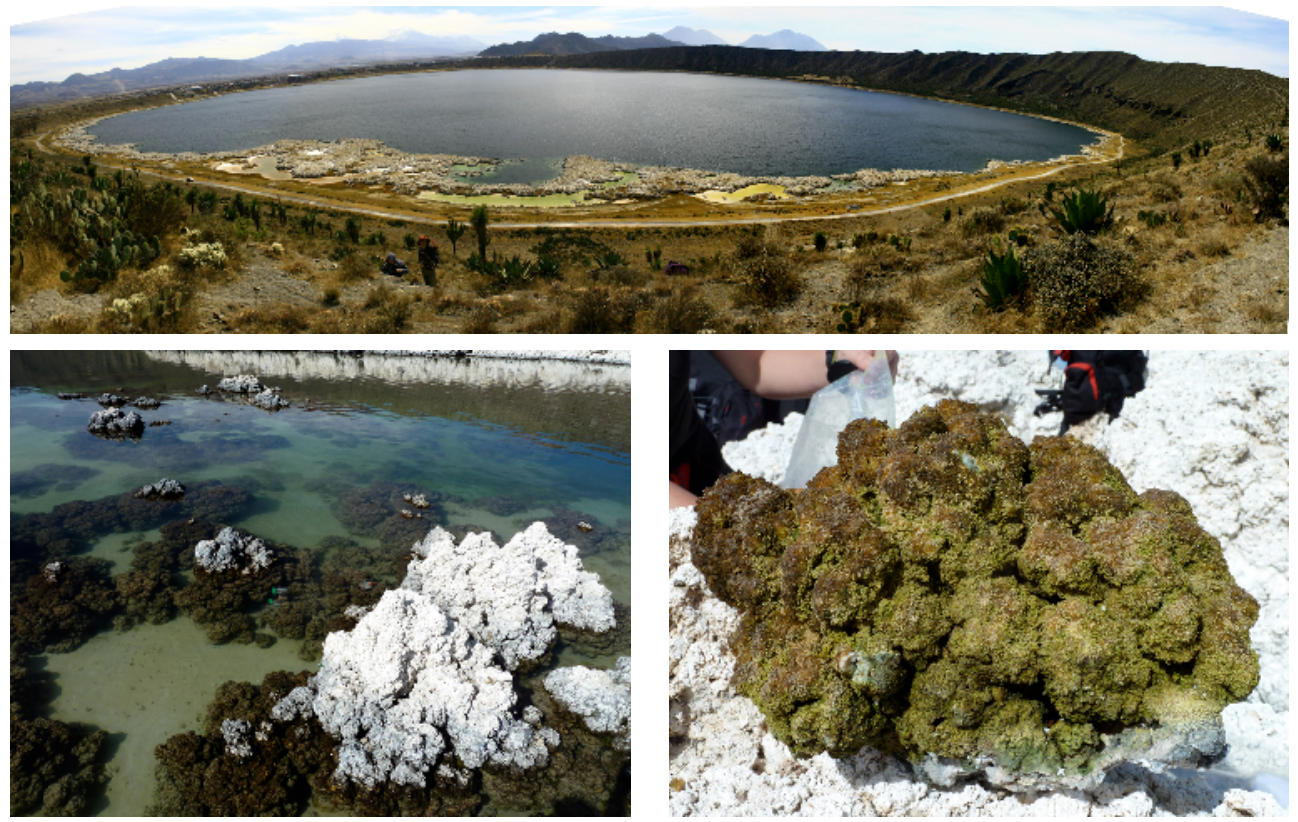

Fig. 1. Lake Alchichica. Top: Panoramic view of the lake showing a fringing barrier formed by the microbialites. Bottom left: emerged sub-fossil (white) and immerged living (green) microbialites. Bottom right: collected living microbialite.

\section{Structure of Prokaryotic and Eukaryotic Communities in Field and Cultured Microbialites from the Alkaline Lake Alchichica (Mexico)}

We aimed at characterizing in detail the microbial communities associated with microbialites at different depths in the lake in order to understand microbial interactions in Alchichica microbialites and ultimately better understand how these form [11]. Indeed, the recurrent presence of particular abundant lineages associated with these organosedimentary systems, may point out to certain specific metabolisms and lead to hypotheses about their potential role on carbonate precipitation. The geomicrobiology of crater lake microbialites remains largely unknown although they resemble their Archaean analogues in the dominance of in situ carbonate precipitation over accretion. Most microbial diversity studies using molecular methods have been conducted so far on marine microbialites. In marine environments, Alpha- and Gammaproteobacteria, Cyanobacteria and Planctomycetales appear to be dominant members of the associated microbial communities [24-31]. In lacustrine microbialites, Firmicutes, Gamma- and Alphaproteobacteria were the most abundant taxa identified in Lake Van microbialites, but these studies were carried out on dry samples that had been stored for nearly 15 years and, hence, likely highly biased [10]. Metagenomic analyses revealed that, similarly to marine microbialites, microbialites from Cuatro Ciénagas were populated by a 
complex community where Cyanobacteria, Alpha- and Gammaproteobacteria and Planctomycetales predominated.

Here, we studied the diversity of archaea, bacteria and protists (microbial eukaryotes) populating the alkaline Lake Alchichica microbialites in both field samples collected along a depth gradient (0-14 m depth) and aquaria samples set up and maintained in the laboratory for more than two years. We used small subunit (SSU) rRNA gene libraries and fingerprinting methods. A total of 1143 bacterial clones (excluding cyanobacteria amplified with specific cyanobacterial primers), 526 cyanobacterial clones (in addition to cyanobacterial clones retrieved with general bacterial primers) and 598 eukaryotic clones were analyzed. Only a low diversity of archaea was detected.

We detected members of up to 20 bacterial phyla or candidate divisions, including lineages possibly involved in microbialite formation, such as sulfate-reducing Deltaproteobacteria but also Firmicutes and very diverse taxa likely able to degrade complex polymeric substances, such as Planctomycetales, Bacteroidetes and Verrucomicrobia. Oxygenic photosynthesizers were dominated by Cyanobacteria, green algae and diatoms. In aquarium microbialites, the early-branching Gloeobacterales represented a significant proportion of oxygenic photosynthesizers. Anoxygenic photosynthesizers were also diverse, comprising members of Alphaproteobacteria and Chloroflexi. Although photosynthetic microorganisms dominated in biomass, heterotrophic lineages were more diverse. This suggests an important role for heterotrophic lineages in this system, which will need to be quantitatively estimated in the future.

Moreover, we observed in the lake a marked shift in the composition of the cyanobacterial community with depth. While the filamentous Oscillatoriales clearly dominated in surface and intermediate depths $(0.5$ and $4 \mathrm{~m})$, Pleurocapsales clearly dominated in deeper samples. Such spatial and temporal variations in dominant cyanobacterial composition have been evidenced before. For instance, Pleurocapsales and Oscillatoriales were also abundant in some marine microbialites from Hamelin Pool [31] but an independent study showed that Chrooccocales dominated another Hamelin pool sample [27]. The same variations were evidenced in Bahamian thrombolites [30] and type 2 stromatolites [26]. For Bahamian stromatolites, it was proposed that a cyclic activity of successive mat types dominated by, successively, Oscillatoriales (Schizothrix) and Pleurocapsales (Solentia) occurs [32]. Although the Bahamas system is very different from Alchichica, these results suggest that dominant cyanobacteria may vary temporally and spatially. Their differential presence may have a significant impact on the organization of the biofilm associated with the microbialites and processes affecting carbonate precipitation as explained in section 3.

The diversity of microbial eukaryotes has been rarely assessed in microbialites before. Some reports based on microscopy observations suggested that eukaryotes could be relevant in microbialite formation [33, 34]. Here, we showed that heterotrophic eukaryotes were dominated by Fungi (including members of the basal Rozellida or Cryptomycota), Choanoflagellida, Nucleariida, Amoebozoa, Alveolata and Stramenopiles. The diversity and relative abundance of many eukaryotic lineages suggest an unforeseen role for protists in microbialite ecology.

Finally, several living microbialite fragments were transferred to laboratory aquaria. A layer of centimetre-sized fragments of dead microbialites was deposited at the bottom of aquaria in order to buffer the solution $\mathrm{pH}$ at 8.9 and chemical composition close to that of the lake. We observed that many lineages from lake microbialites were successfully maintained in aquaria for more than two years in the laboratory. Interestingly, the diversity detected in aquarium microbialites was unexpectedly even higher than in field samples, possibly due to the more stable and favorable laboratory conditions. The maintenance of highly diverse natural microbialites in laboratory aquaria holds promise to study the role of different metabolisms in the formation of these structures under controlled conditions. Indeed, this opens the possibility to carry out biomineralization experiments using a complex and fairly genuine diverse microbial community. 


\section{Evidence of aragonite formation by Pleurocapsales in Lake Alchichica and study of cyanobacterial calcification at the submicrometer-scale}

\subsection{Evidence of specific associations between aragonite and Pleurocapsales [17]}

We imaged the cyanobacteria-carbonate interface in Lake Alchichica microbialites by coupling three-dimensional imaging of molecular fluorescence emitted by pigmented microorganisms using confocal laser scanning microscopy (CLSM), scanning electron microscopy and Raman microspectroscopy on associated minerals in order to explore potential biogenic carbonate precipitation [17]. Indeed, despite considerable progress in our understanding of the microbial diversity associated with different microbialites and their mineralogy, the question of whether or not some microorganisms play an important active role in promoting mineral precipitation is yet unsettled [e. g., 35].

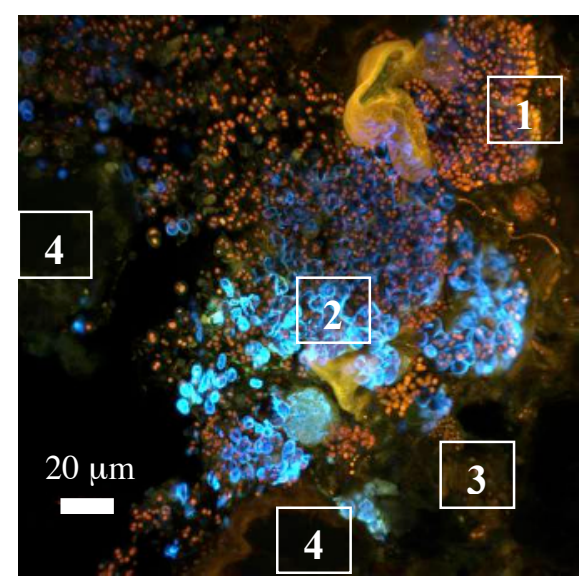

Fig. 2. CLSM observation performed on a Alchichica microbialite section. This composite image shows cell autofluorescence induced by laser excitation at 405, 488 and $515 \mathrm{~nm}$. Artifical colours are associated with different pigments: in red (1), photosynthetic pigments (phycobiliproteins \& chlorophyll). In blue (2), fluorescent sheaths of some cyanobacteria. In green (3) sheaths and carotenoïds, detectable in poorly active or degraded cells. Dark (4), on this image, minerals appear more or less dark depending on their natures and content in organic matter [17]. Width of the image is $200 \mu \mathrm{m}$.

Lake Alchichica microbialites are mostly composed of hydromagnesite, an hydrated magnesium carbonate $(\mathrm{Mg} 5(\mathrm{CO} 3) 4(\mathrm{OH}) 2 \bullet 4(\mathrm{H} 2 \mathrm{O}))$ and some patches of aragonite $\left(\mathrm{CaCO}_{3}\right)$. Morphology and pigment-content analysis of dominant photosynthetic microorganisms by CLSM revealed up to 6 different cyanobacterial morphotypes belonging to Oscillatoriales, Chroococcales, Nostocales, and Pleurocapsales, as well as several diatoms and other eukaryotic microalgae in agreement with bulk molecular diversity analyses. Interestingly, one of these morphotypes, Pleurocapsa-like, appeared specifically associated with aragonite minerals, some parts of actively growing Pleurocapsa-like colonies being always aragonite-encrusted. We hypothesized that actively growing cells of Pleurocapsales modify local environmental conditions via the concomitant photosynthesis-derived alkalinization of their local environment and the specific accumulation of $\mathrm{Ca}^{2+}$ in an external fibrous layer (F-layer) of vegetative cells, not present in the other cyanobacterial phyla, favoring aragonite precipitation at the expense of hydromagnesite where these microorganisms are present. In doing so, Pleurocapsales become encrusted and progressively fossilize [18]. Therefore, at least part of the 
mineral precipitation in Alchichica microbialites is biogenic and the type of biominerals formed may depend on the nature of the phylogenetic lineage involved.

Interestingly, members of the Pleurocapsales seem to be quantitatively abundant and specific active players in mineral formation not only in Alchichica microbialites but also in other microbialite systems. Indeed, Pleurocapsales were detected in all microbialite fragments collected in the Alchichica lake, especially at greater depths [11] but phylotypes of Pleurocapsales related to those identified in Alchichica microbialites have also been detected in numerous other microbialite systems, such as in Lake Van, Turkey [10], Satonda, Indonesia [36], Shark Bay, Austrialia [27] and the Bahamian stromatolites [26]. Therefore, Pleurocapsales seem particularly well adapted to microbialite ecosystems and may play an important role as ecological architects of microbialite structures. Moreover, these observations may provide clues to identify lineage-specific biosignatures in fossil microbialites from modern to Precambrian times.

\subsection{Early fossilization of Pleurocapsales in modern microbialites (Couradeau et al., in rev)}

The self-encrustation of Pleurocapsales by aragonite offers a good example of how microorganisms can become fossilized. Indeed, encrustation of bacterial cells by minerals, which takes place over timescales of a few hours or days facilitates the preservation of the morphology and sometimes ultrastructure of bacteria and blocks or slows down the degradation of bacterial organic molecules [e.g., 37-39]. A detailed understanding of the processes leading to fossilization is crucial. Indeed, the search for microbial cell fossils (microfossils) in the geological record has been a long-term challenge causing multiple debates [e.g., 40, 41]. Part of the problem comes from the difficulty to identify microfossils unambiguously, since they are small and their morphology can be confused with abiotic biomorphs [42]. Moreover, it is yet not clear what taxonomic biases can occur in the fossil record and what is the origin of these biases.

We studied the initial stages of this fossilization process affecting Pleurocapsales cells in Alchichica microbialites. Scanning electron microscopy showed that encrustation gradients from non-encrusted to totally encrusted cells span distances of only a few hundred micrometers. Cells exhibiting increased levels of encrustation along this gradient were studied down to the nm-scale by transmission electron microscopy (Figure 3) and synchrotron-based x-ray microscopy. Two different types of aragonite crystals forming in association with Pleurocapsales cells were observed: one type consisted in needle-shaped nano-crystals growing outward from the cells with a crystallographic orientation perpendicular to the cell wall, and another type was composed of larger crystals that progressively filled the cell interior. As mentioned above, the particular sheath at the surface of Pleurocapsales cells might provide a suitable template for mineral nucleation explaining the formation of aragonite needles perpendicular to the cells' surfaces. In contrast, larger crystals filling the cell interior most likely form post-mortem. Organic matter (OM), initially co-localized with the cell, decreased in concentration and dispersed away from the cell while crystal growth occurred. As encrustation developed, OM progressively disappeared, but remaining OM showed the same spectroscopic signature. Some residual pigments were preserved as indicated by the detection of autofluorescence by CLSM. Pigments are especially recalcitrant molecules that can be preserved in sediments [43] and can be used as molecular fossil diagnostic for photosynthetic organisms. In the most advanced stages of fossilization, only the relative textural organization of the two types of aragonite recorded the initial cell morphology and spatial distribution. It will be important in the future to assess the stability of this kind of textural biosignature upon aging and to look for it in increasingly old fossil microbialites. 


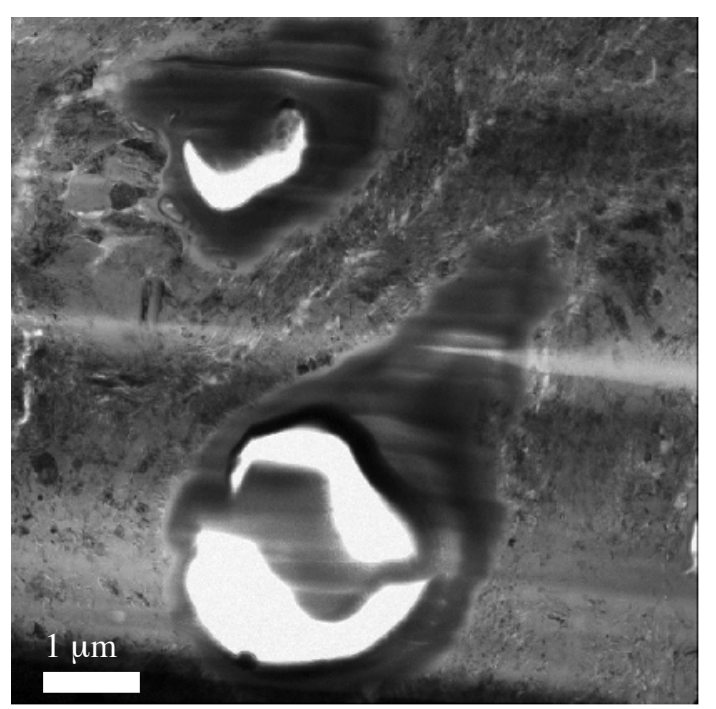

Fig. 3. Transmission electron microscopy image of two Pleurocapsales cells (dark smooth area) encrusted by aragonite crystals grey surrounding matrix) and sectioned by focused ion beam milling [18].

\section{Discovery of an early-branching microbialite cyanobacterium forming intracellular carbonates}

As explained in the previous section, at least some cyanobacteria contribute significantly to the formation of microbialites by triggering $\mathrm{CaCO}_{3}$ precipitation. The reaction of $\mathrm{CaCO}_{3}$ precipitation can be written as:

$$
\mathrm{Ca}^{2+}+2 \mathrm{HCO}_{3}^{-} \rightarrow \mathrm{CaCO}_{3}+\mathrm{CO}_{2}+\mathrm{H}_{2} \mathrm{O}
$$

At first order, cyanobacteria trigger that reaction by fixing $\mathrm{CO}_{2}$ through photosynthesis, hence displacing equilibrium (1) towards the right, increasing supersaturation and overcoming kinetic barriers. A micro-environment then develops around the cells where precipitation occurs. As a result, and as mentioned in the section above, cells may get entombed and form microfossils [17]. Although the exact timing of cyanobacteria appearance is still debated [e.g., 44], there is a consensus on an age older than 2.3 Gyrs, i.e., the start of atmosphere oxygenation [e.g., 45]. Yet, there have been many debates on whether Palaeoproterozoic and Mesoproterozoic (2500-1000 Myr) showed evidence of direct (i.e., on the cells) or indirect mediation of calcification by bacteria [e.g., 2]. These debates were based on varying textural interpretations of purported filamentous microfossils and comparisons with modern analogues. The oldest undisputed traces of calcified cyanobacteria are Girvanella microfossils found in stromatolites of the Draken Formation (Spitsbergen) dated at 750700 Myr [46].

The huge difference in timing between first microfossils of cyanobacteria and first microfossils of calcified cyanobacteria was called the 'Precambrian Enigma' by Riding [47]: "if seawater saturation state with respect to $\mathrm{CaCO}_{3}$ minerals was high during much of the Proterozoic (...) then why was cyanobacterial calcification so poorly developed in comparison to the Palaeozoic"?

In the current view of cyanobacteria-induced calcification, cyanobacteria import carbon under the form of $\mathrm{HCO}_{3}{ }^{-}$especially in environments where dissolved $\mathrm{CO}_{2}$ is limiting. $\mathrm{HCO}_{3}{ }^{-}$is then converted to $\mathrm{CO}_{2}$ and $\mathrm{CO}_{3}{ }^{2-}$ and/or $\mathrm{OH}^{-}$(both carbon species are mentioned in the literature; there is an 
equilibrium between $\mathrm{HCO}_{3}{ }^{-}$and $\mathrm{CO}_{3}{ }^{2-}$ in the cytoplasm that depends on $\mathrm{pH}$ ). $\mathrm{CO}_{2}$ is then fixed by photosynthesis into organic carbon while $\mathrm{CO}_{3}{ }^{2-}$ and/or $\mathrm{OH}^{-}$are exported to the extracellular medium. The mechanism of this export remains mysterious. Anyhow, this raises the saturation of the surrounding solution with various carbonate minerals (depending on the cation content of the extracellular solution). An additional source of oversaturation is provided by an active export of $\mathrm{Ca}^{2+}$ from the cells coupled with import of $\mathrm{H}^{+}$[48]. Finally, some cyanobacteria cells produce extracellular polymeric substance (EPS) that form a diffusion-limited micro-environment where $\mathrm{pH}$ and other chemical gradients (e.g. $\left[\mathrm{Ca}^{2+}\right]$ ) build up. As a result, $\mathrm{CaCO}_{3}$ crystals precipitate around the cells and entomb them [e.g., 17]. Alternatively, some planktonic bacteria produce a proteinaceous surface layer that provides an effective nucleating site and can be shed subsequently [49]. In any case, calcification by cyanobacteria has been invariably considered as an extracellular process.

We recently questioned this paradigm by discovering a cyanobacterial species, Candidatus Gloeomargarita lithophora, forming intracellular carbonate inclusions [19] (Figure 4).

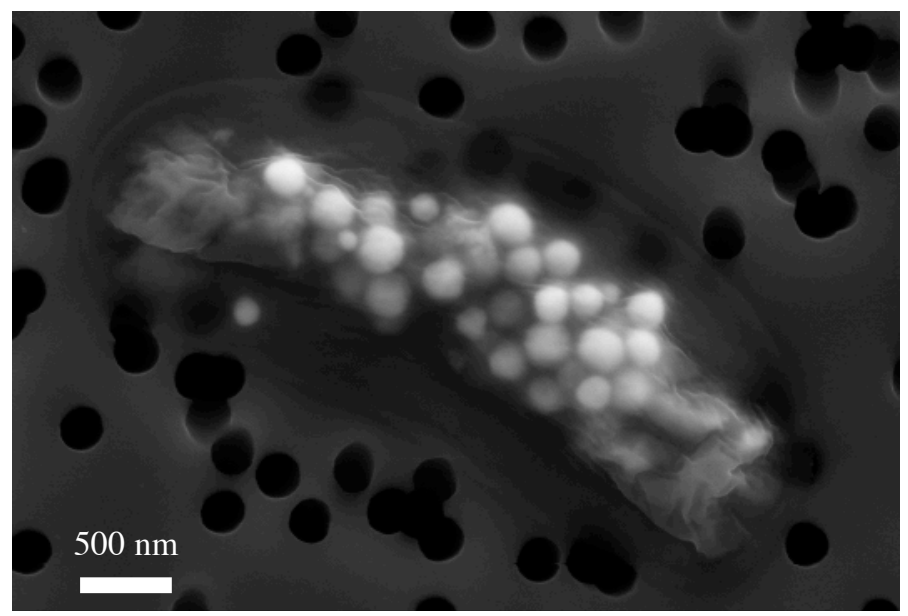

Fig. 4. Scanning electron microscopy image of a Candidatus Gloeomargarita lithophora cell deposited on a $0.2 \mu \mathrm{m}$ pore size filter and showing intracellular carbone inclusions (bright spheres).

This intracellularly calcifying cyanobacterium, coexist with extracellularly calcifying cyanobacteria in the Alchichica microbialites. Very interestingly, Candidatus Gloeomargarita lithophora is branching deeply in the Cyanobacteria phylogenetic tree. Overall, Candidatus Gloeomargarita lithophora mineral inclusions can fill up to $6 \%$ of the total cell volume, with some variations. This represents a rise in the density of the cells of $\sim 12 \%$. Only hydromagnesite $\left[\mathrm{Mg}_{5}\left(\mathrm{CO}_{3}\right)_{4}(\mathrm{OH})_{2} \bullet 4\left(\mathrm{H}_{2} \mathrm{O}\right)\right]$ and aragonite $\left(\mathrm{CaCO}_{3}\right)$ form in the aquarium from which Candidatus Gloeomargarita lithophora was isolated as shown by x-ray diffraction, SEM analyses and in agreement with thermodynamic calculations. Surprisingly, intracellular inclusions formed by Candidatus Gloeomargarita lithophora have a very different stoichiometry: $\left(\mathrm{Sr}_{1} \mathrm{Ba}_{2.7} \mathrm{Mg}_{1.4} \mathrm{Ca}_{0.9}\right) \mathrm{Ca}_{6} \mathrm{Mg}\left(\mathrm{CO}_{3}\right)_{13}$. This represents a 90-fold and 1370 -fold increase, respectively in inclusion $\mathrm{Sr} / \mathrm{Ca}$ and $\mathrm{Ba} / \mathrm{Ca}$ ratios as compared to the extracellular solution. This is surprising since abiotic carbonate precipitation should not induce fractionation of $\mathrm{Sr}$ or $\mathrm{Ba}$ over $\mathrm{Ca}$. Another surpise is that these intracellular minerals are amorphous by electron diffraction. Amorphous Ca-carbonates have received a large attention since they are considered as precursor phases important for the control of biomineralization by eukaryotic organisms and possibly serving as an easy remobilizable source of calcium and carbonate. Altogether, these observations suggest that Candidatus Gloeomargarita lithophora exerts some control on intracellular formation. This report moreover extends the chemical diversity of known amorphous carbonates and occurrence to bacterial systems. Whether such inclusions have a particular function in cells and what is the evolutionary history of this process will have to be determined by future studies. At least, 
it is likely that intracellular carbonate precipitation in this cyanobacterium likely influences its biology and ecology. First, as mentioned above, these precipitates alter cell buoyancy. Whereas gas vesicles function as flotation devices in planktonic cyanobacteria and other prokaryotes, intracellular carbonates may serve as ballasts providing, in contrast, an adaptation to a benthic mode of life. Second, the formation of intracellular carbonates implies that the alkalinity excess produced by cyanobacteria during photosynthetic carbon fixation is at least partly trapped within the amorphous carbonate inclusions. Therefore, carbonate precipitation could act as a $\mathrm{pH}$ buffering system leading to an efficient carbon concentrating mechanism and, hence, a high photosynthesis rate.

Moreover, one can speculate about the two main conceptual possibilities: 1- intracellular biomineralization is ancestral. In that case, we need to change our view of how cyanobacteria contributed to calcification in ancient environments. In such a case, no extracellular cell calcification and subsequent microfossil formation may have been possible in ancient times, explaining why we do not find fossil calcified cyanobacteria in the old fossil record. In contrast, chemical heterogeneities in carbonate deposits, if preservable, might be expected. Biomineralization may have become extracellular secondarily possibly by appearance of a process inhibiting intracellular precipitation 2- Alternatively, extracellular biomineralization may have been ancestral. Something changed at least in the Candidatus Gloeomargarita lithophora lineage so that biomineralization became intracellular for these bacteria. Understanding which change led to internalization of biomineralization and whether it was an evolutionary innovation are far-reaching yet first order questions for those interested in geosphere/biosphere interactions.

\section{References}

1. R. V. Burne, L. S. Moore, Palaios 2, 241 (1987)

2. W. Altermann, J. Kaźmierczak, A. Oren, D. T. Wright, Geobiology 4, 147 (2006)

3. L. J. Stal, The ecology of cyanobacteria (Kluwer Academic Publishers, Dordrecht, 2000)

4. E. Kalkowsky, Zeitschrift der Deutschen geologischen Gesellschaft 60, 68 (1908)

5. J. P. Grotzinger, D. H. Rothman, Nature 383, 423 (1996)

6. L. K. Baumgartner, R. P. Reid, C. Dupraz, A. W. Decho, D. H. Buckley, J. R. Spear, K. M. Przekop, P. T. Visscher, Sed. Geol. 185, 131 (2006)

7. T. Bosak T, S. E. Greene, D. K. Newman, Geobiol. 5, 119 (2007)

8. K. Benzerara, N. Menguy, P. Lopez-Garcia, T. H. Yoon, J. Kaźmierczak, T. Tyliszczak, F. Guyot, G. E. Brown, Jr., Proc. Ntl. Acad. Sci. USA 103, 9440 (2006)

9. O. Braissant, A. W. Decho, C. Dupraz, C. Glunk, K. M. Przekop, P. T. Visscher, Geobiol. 5, 401 (2007)

10. P. López-García, J. Kazmierczak, K. Benzerara, S. Kempe, F. Guyot, D. Moreira Extremophiles 9, 263 (2005)

11. E. Couradeau, K. Benzerara, D. Moreira, E. Gerard, J. Kazmierczak, R. Tavera, P. LopezGarcia, Plos One 6, e28767 (2011)

12. K. Benzerara, N. Menguy, C.R. Palevol 8, 617 (2009)

13. K. Lepot, K. Benzerara, G. E. Brown, Jr., P. Philippot, Nature Geoscience, 1, 118 (2008)

14. K. Lepot, K. Benzerara, N. Rividi, M. Cotte, G. E. Brown Jr, P. Philippot, Geochim. Cosmochim. Acta 73, 6579 (2009)

15. G. Arp, A. Reimer, J. Reitner, Science 292, 1701 (2001)

16. N. Planavsky, R. P. Reid, T. W. Lyons, K. L. Myshrall, P. T. Visscher, Geobiol. 7, 566 (2009)

17. E. Gerard, B. Menez, E. Couradeau, D. Moreira, K. Benzerara, R. Tavera, P. Lopez-Garcia, ISME J. (to be published)

18. E. Couradeau, K. Benzerara, E. Gérard, I. Estève, D. Moreira, R. Tavera, P. López-García, Biogeoscience, in rev.

19. E. Couradeau, K. Benzerara, E. Gerard, D. Moreira, S. Bernard, G. E. Brown Jr, P. LopezGarcia, Science 336, 459 (2012) 
20. J. Kaźmierczak, S. Kempe, B. Kremer, P. López-García, D. Moreira, R. Tavera, Facies 57,543 (2011)

21. M. Macek, D. Pestova, M. E. Martinez Perez, Hidrobiologica 18, 25 (2008)

22. J. Alcocer, A. E. Filonov, Env. Geol. 53, 777 (2007)

23. M. A. Armienta, G. Vilaclara, S. De la Cruz-Reyna, S. Ramos, N. Ceniceros, O. Cruz, A. Aguayo, F. Arcega-Cabrera, J. Volcanol. Geotherm. Res. 178, 249 (2008)

24. M. A. Allen, F. Goh, B. P. Burns, B. A. Neilan, Geobiol 7, 82 (2009)

25. L. K. Baumgartner, J. R. Spear, D. H. Buckley, N. R. Pace, R. P. Reid, C. Dupraz, P. T. Visscher, Environ. Microbiol. 11, 2710 (2009)

26. J. S. Foster, S. J. Green, S. R. Ahrendt, S. Golubic, R. P. Reid, K. L. Hetherington, L. Bebout, ISME J. 3, 573 (2009)

27. F. Goh, M. A. Allen, S. Leuko,T. Kawaguchi, A. W. Decho, B. P. Burns, B. A. Neilan, ISME J. 3, 383 (2009)

28. S. A. Havemann, J. S. Foster, Appl. Env. Microbiol. 74, 7410 (2008)

29. J. M. Mobberley, M. C. Ortega, J. S. Foster, Environ. Microbiol. 14, 82 (2012)

30. K. L. Myshrall, J. M. Mobberley, S. J. Green, P. T. Visscher, S. A. Havemann, R. P. Reid, J. S. Foster, Geobiol. 8, 337 (2010)

31. D. Papineau, J. J. Walker, S. J. Mojzsis, N. R. Pace, Appl. Environ. Microbiol. 71, 4822 (2005)

32. R. P. Reid, P. T. Visscher, A. W. Decho, J. F. Stolz, B. M. Bebout, C. Dupraz, I. G. Macintyre, H. W. Paerl, J. L. Pinckney, L. Prufert-Bebout, T. F. Steppe, D. J. DesMarais, Nature 406, 989 (2000)

33. S. Al-Qassab, W. J. Lee, S. Murray, A. G. B. Simpson, D. J. Patterson, Acta Protozool. 41, 91 (2002)

34. B. M. Winsborough, S. Golubic, J. Phycol. 23, 195 (1987)

35. K. Benzerara, A. Meibom, Q. Gautier, J. Kazmierczak, J. Stolarski, N. Menguy, G. E. Brown Jr, Geological Society of London Special Publications, 336, 211 (2010)

36. S. Kempe, J. Kazmierczak, Chem. Geol. 81, 299 (1990)

37. K. Benzerara, N. Menguy, F. Guyot, F. Skouri, G. de Luca, M. Barakat, T. Heulin, Earth Planet. Sci. Lett. 228, 439 (2004)

38. J. Miot, K. Maclellan, K. Benzerara, N. Boisset, Geobiol. 9, 459 (2011)

39. J. Cosmidis, K. Benzerara, E. Gheerbrant, I. Esteve, B. Bouya, M. Amaghzaz, Geobiol. 11, 139 (2013)

40. M. D. Brasier, O. R. Green, A. P. Jephcoat, A. K. Kleppe, M. J. Van Kranendonk, J. F. Lindsay, A. Steele, N. V. Grassineau, Nature 416, 76 (2002)

41. J. W. Schopf, A. B. Kudryavtsev, D. G. Agresti, T. J. Wdowiak, A. D. Czaja, Nature 416, 73 (2002)

42. J. M. Garcia-Ruiz, A. Carnerup, A. G. Christy, N. J. Welham, S. T. Hyde, Astrobiol. 2, 353 (2002)

43. P. R. Leavitt, R. D. Vinebrooke, D. B. Donald, J. P. Smol, D. W. Schindler, Nature 388, 457 (1997)

44. L. I. Falcon, S. Magallon, A. Castillo, ISME J. 4, 777 (2010)

45. J. Farquhar, A. L. Zerkle, A. Bekker, Photosynthesis Res. 107, 11 (2011)

46. A.H. Knoll, K. Swett, J. Mark, J. Paleontol. 65, 531-570 (1991)

47. R. Riding, Geobiol. 4, 299 (2006)

48. J. B. Thompson, S. SchultzeLam, T. J. Beveridge, D. J. DesMarais, Limnol. Oceano. 42, 133 (1997)

49. S. SchultzeLam, G. Harauz, T. J. Beveridge, J. Bacteriol. 174, 7971 (1992) 